\title{
Impact of rapid investigation clinic on timeliness of lung cancer diagnosis and treatment
}

\author{
Nicole Ezer ${ }^{1,2}$, Asma Navasakulpong $^{3}$, Kevin Schwartzman ${ }^{1,2}$, Linda Ofiara ${ }^{2}$ and Anne V. Gonzalez ${ }^{1,2 *}$
}

\begin{abstract}
Background: Guidelines recommend timely evaluation of patients with suspected lung cancer. We evaluated the impact of a Rapid Investigation Clinic (RIC) on timeliness of lung cancer diagnosis and treatment between February 2010 and December 2011.

Methods: Investigation within the RIC was conducted by a pulmonologist and a nurse clinician. Controls were patients with lung cancer, investigated outside the RIC at the same institution during the same time period. The primary outcome was time between first contact with a local physician for suspected lung cancer (TO) and first treatment. Factors associated with the delay from T0 to first treatment were examined using multivariate analysis. Completeness of lung cancer staging according to guidelines was assessed.
\end{abstract}

Results: A total of 195 patients were investigated within the RIC vs. 132 patients outside the RIC. The median delay between T0 and first treatment was 65 days (interquartile range [IQR] 46-92 days) in the RIC and 78 days (IQR 49119 days) in the non-RIC patients ( $p \leq 0.01$ ). Time from T0 to pathological diagnosis was shorter in the RIC (median 26 days; IQR 14-42 days) vs. non-RIC patients (median 40 days; IQR 16-68 days). In multivariate analysis, investigation in the RIC was associated with a reduction in time to first treatment of 24 days (95\% confidence interval [CI] 12-35 days) when adjusted for relevant confounders. Guideline-concordant investigation occurred more frequently in RIC patients, based on the quality indicators examined.

Conclusions: A Rapid Investigation Clinic reduces delays to lung cancer diagnosis and treatment, and impacts quality of care.

Keywords: Lung cancer diagnosis, Neoplasm staging, Timeliness, Delay

\section{Background}

Lung cancer remains the leading cause of cancer death for both men and women [1]. Timeliness of lung cancer care is an important quality indicator; however, standards for investigation of new lung cancer patients vary. With the advent of Computed tomography (CT) screening for lung cancer [2] the number of patients requiring investigation is likely to increase. This will require evidence-based strategies aimed at improving guidelineconcordant care and minimizing delays.

\footnotetext{
* Correspondence: anne.gonzalez@mcgill.ca

${ }^{1}$ Respiratory Epidemiology and Clinical Research Unit, Montreal Chest Institute, McGill University Health Centre, Montreal, QC, Canada

${ }^{2}$ Respiratory Division, McGill University Health Centre, Montreal, QC, Canada

Full list of author information is available at the end of the article
}

Accurate lung cancer diagnosis and staging requires various imaging studies and procedures. Positron Emission Tomography (PET) scanning detects unsuspected metastatic disease and reduces non-curative surgical resections [3]. Minimally invasive needle techniques such as endobronchial ultrasound-guided needle aspiration (EBUS) are now considered the test of first choice to confirm mediastinal disease [4]. Work-up of patients with suspected lung cancer requires ready access to these tests and adequate coordination of care, in addition to multi-disciplinary input.

The 2011 National Institute for Health and Clinical Excellence (NICE) guidelines recommend that rapid access clinics should be provided, where possible, for the investigation of patients with suspected lung cancer [5]. The most recent American College of Chest Physicians 
(ACCP) lung cancer guidelines suggest that efforts be made to deliver "timely" care [6]. At the McGill University Health Centre (MUHC), a Rapid Investigation Clinic (RIC) was established to coordinate and accelerate the workup of patients with suspected lung cancer. The aim of the study was to assess the impact of this model of care on timeliness of lung cancer diagnosis, staging and treatment. The impact of the RIC on the delivery of a guideline-concordant investigation was also examined.

\section{Methods}

The Rapid Investigation Clinic (RIC) was established in February 2010. The RIC operates twice a week, and is staffed by a rotating pulmonary physician and nurseclinician. The nurse-clinician monitors the investigation progress, assists with coordination of care, and provides patients with the necessary psychosocial support. At initial encounter, preference is given to the invasive diagnostic procedure felt to have the best yield/risk ratio based on CT findings. Procedures that allow simultaneous diagnosis and staging are favored. Patients are staged according to the 2009 staging system [7], and the 2007 American College of Chest Physicians guidelines for lung cancer diagnosis and staging were followed during the study period [8]. Patients in the RIC and non-RIC groups had access to the same imaging studies and diagnostic procedures within the institution.

An institutional database of all patients with a pathological diagnosis of lung cancer was established in November 2008. A prospective database of patients evaluated in the RIC was established in 2010 and maintained by a registrar, to facilitate delays surveillance. Patients investigated within the RIC between February 2010 and December 2011, in whom a diagnosis of lung cancer was confirmed, are included in this analysis (RIC patients). Patients investigated within our institution but outside the RIC, whether by other "non-RIC" pulmonologists or thoracic surgeons, and in whom a diagnosis of lung cancer was confirmed, constituted the comparison group. The "non-RIC" physicians elected to continue investigation of patients with suspected lung cancer within their own clinics, as was being done prior to RIC implementation. Patients with a second lung cancer diagnosis, patients partially investigated outside the institution (e.g. referred only for a specific diagnostic procedure or for surgery), patients undergoing re-staging after initial treatment for lung cancer, and patients investigated during a hospitalization were excluded.

The data extracted from electronic health records included patient demographics, date and type of imaging studies and invasive procedures, histopathological diagnosis, disease stage, date and type of treatments. Performance status was extracted from consultation notes.
Time 0 (T0) refers to the first visit with any MUHC physician for suspected lung cancer, and was defined as follows: 1) In symptomatic patients T0 was the first visit in the ER which triggered further testing for lung cancer; 2) If lung cancer was suspected from imaging, T0 was the visit date after the imaging study, which prompted further investigation; 3) If the patient was followed by a pulmonary physician for an alternate diagnosis or a lung nodule and there was a suspicion of lung cancer, T0 was considered the visit that triggered additional tests; 4) In patients referred to the RIC by any physician, T0 was considered the date of referral. Hence, T0 was not the date of first visit to the RIC, but rather the visit that triggered the lung cancer investigation and/or RIC referral. All delays were measured from T0. The specialty of the physician who evaluated the patient at T0 was recorded.

All invasive diagnostic procedures performed were reviewed. These included bronchoscopy, EBUS (linear or radial), transthoracic needle aspiration (TTNA), endoscopic ultrasound (EUS) and mediastinoscopy. Procedures aimed at sampling a peripheral lung nodule or mass, and procedures aimed at sampling hilar and/or mediastinal nodes were examined separately. The number of non-diagnostic procedures was documented in RIC and non-RIC patients. The invasive diagnostic procedure that first provided a pathological diagnosis of lung cancer was recorded.

The primary outcome was the time interval (in days) between first contact with a local physician for suspected lung cancer (T0) and date of first treatment. First treatment encompassed surgery or radiosurgery for early stage lung cancer, and chemotherapy or combined chemo-radiotherapy for advanced stage disease. The time interval from $\mathrm{T} 0$ to date of tissue diagnosis (i.e. date of a pathology report that confirms the diagnosis), and the interval from T0 to the date all staging investigations are completed were also examined. "Staging completed" refers to the date of the last test (imaging study or invasive procedure) that completes the lung cancer investigation according to the ACCP 2007 guidelines [8]. Quality indicators of guideline-concordant investigation were compared in the RIC and non-RIC groups. These included: PET scanning in stage I-II patients treated with surgical resection, brain imaging prior to curative-intent treatment in stage III non-small cell lung cancer (NSCLC), and brain imaging for small cell lung cancer (SCLC). The proportion of patients referred to multidisciplinary lung cancer clinic and/or the lung cancer tumor board was recorded.

Time intervals are reported as median and interquartile range, and were compared using the Wilcoxon rank sum test. Linear regression analysis was used to examine factors thought to be associated with delay from $\mathrm{T} 0$ to first treatment. A multivariate model was constructed 
with the following covariates: age ( $\leq 75$ or $>75$ years), sex, performance status (Eastern Cooperative Oncology Group (ECOG) $0-1$ versus $\geq 2$ ), lung cancer type (NSCLC versus SCLC), investigation in the RIC versus outside the RIC, inclusion of EBUS and PET scan in the lung cancer investigation, and number of non-diagnostic tests $(0,1$ or $\geq 2)$. To examine the impact of disease stage, the multivariate analysis was repeated in the subgroup of patients with NSCLC. Quality metrics were compared using a chi-squared test or Fisher's exact test, as appropriate.

The study was approved by the Research Ethics Board of the MUHC. All analyses were performed using SAS version 9.3. Graphs were designed using GraphPad Prism.

\section{Results}

There were 195 patients in the RIC group and 132 patients in the non-RIC group. Baseline characteristics are detailed in Table 1. The RIC group included a higher proportion of patients with SCLC (13\%) compared to the non-RIC group (5\%). Performance status was similar in both groups. Among RIC patients, the physician who initiated the lung cancer investigation and referred to the RIC (type of 0 physician) was more likely to be a pulmonologist (93\%), while the investigation of non-RIC patients was initiated by both pulmonologists $(67 \%)$ and

Table 1 Baseline characteristics of patients investigated within the Rapid Investigation Clinic (RIC) and those investigated at the same institution (Non-RIC)

\begin{tabular}{lllr}
\hline Characteristics & RIC (N=195) & Non-RIC (N=132) & $p$-value \\
\hline Age in years (mean \pm SD) & $69(9)$ & $68(10)$ & 0.55 \\
Male, N (\%) & $94(48)$ & $68(52)$ & 0.57 \\
NSCLC, N (\%) & $169(87)$ & $125(95)$ & $<0.01$ \\
$\quad$ Stage I-II & $51(26)$ & $55(42)$ & \\
Stage III-IV & $118(61)$ & $70(53)$ & 0.29 \\
SCLC, N (\%) & $26(13)$ & $7(5)$ & 0.13 \\
Extensive Stage & $14(7)$ & $3(2)$ & \\
Limited Stage & $12(6)$ & $4(3)$ & $<0.01$ \\
Performance Status, N (\%) & & & \\
ECOG 0-1 & $162(83)$ & $118(90)$ & \\
ECOG 2-3 & $33(17)$ & $14(11)$ & \\
Type of T0 Physician, N (\%) & & & \\
Pulmonologist & $181(93)$ & $89(67)$ & \\
Thoracic surgeon & - & $35(27)$ & $4(3)$ \\
Medical oncology & $4(2)$ & $6(3)$ & - \\
Internal medicine & $4(2)$ & $4(3)$ & \\
Other &
\end{tabular}

${ }^{a}$ Baseline characteristics were compared using the chi-squared test for categorical variables, and the Student $\mathrm{t}$-test for continuous variables thoracic surgeons (27\%). During the study period, 103 patients evaluated within the RIC ultimately did not have a diagnosis of lung cancer. These patients were excluded from the analysis. The majority were diagnosed with non-malignant lung pathologies (including sarcoidosis); 14 patients had other primary malignancies; 28 patients did not pursue investigation due to poor performance status; and one patient was diagnosed with a carcinoid tumor.

The number of invasive diagnostic procedures performed was similar in RIC and non-RIC patients (Table 2). The invasive procedures providing the first pathological evidence of lung cancer were directed at lung masses or nodules in $60 \%$ of patients in the RIC and $56 \%$ of the non-RIC groups $(p=0.42)$. These were directed at lymph nodes in $26 \%$ of the RIC and $23 \%$ of the non-RIC patients $(p=0.22)$ (Table 3$)$. The last test performed to complete lung cancer diagnosis and staging was most frequently an imaging study. In particular, PET scan was the last test in $48 \%$ of RIC and $36 \%$ of non-RIC patients (Table 4).

The median delay between $\mathrm{T} 0$ and first lung cancer treatment was 65 days (interquartile range [IQR] 4692 days) for RIC versus 78 days (IQR 49-119) for non-RIC patients $(p=0.01)$. The median delay to first chemotherapy or radiotherapy was significantly reduced in RIC patients $(p=0.01)$, while time to surgery was similar in RIC and non-RIC patients $(p=n s)$. There was no significant difference in time to staging being completed $(p=0.39)$, however time to pathological diagnosis of lung cancer was reduced significantly in the RIC patients $(p<0.01)$ (Fig. 1).

In the multivariate logistic regression analysis, significant predictors of longer intervals to first treatment were being investigated outside the RIC, a pathological diagnosis of small cell lung cancer, age $>75$ years, inclusion of PET scan in the work-up, and increasing numbers of non-diagnostic tests (Table 5). Worse performance

Table 2 Number and type of invasive diagnostic procedures performed in RIC versus non-RIC patients

\begin{tabular}{l} 
Patients who underwent a \\
given number of invasive \\
diagnostic procedures (\%) \\
\hline RIC $(N=195) \quad$ Non-RIC $(N=132)$
\end{tabular}

Total number of invasive diagnostic procedures performed

\begin{tabular}{lll}
$0^{\text {a }}$ & $9(5)$ & $10(8)$ \\
1 & $99(51)$ & $68(51)$ \\
2 & $67(34)$ & $41(31)$ \\
$\geq 3$ & $20(10)$ & $13(9)$ \\
\hline
\end{tabular}

ancludes patients with no invasive procedure performed, and those with pathology only confirmed at the time of surgical resection (wedge resection, lobectomy or pneumonectomy) 
Table 3 Type of invasive procedures providing the first tissue diagnosis, in RIC versus non-RIC patients

\begin{tabular}{|c|c|c|}
\hline & \multicolumn{2}{|c|}{$\begin{array}{l}\text { Number of patients in } \\
\text { whom a given type of } \\
\text { procedure provided the } \\
\text { tissue diagnosis (\%) }\end{array}$} \\
\hline & $\mathrm{RIC}(N=195)$ & $\begin{array}{l}\text { Non-RIC } \\
(N=132)\end{array}$ \\
\hline $\begin{array}{l}\text { Lung mass or peripheral } \\
\text { nodule sampling }\end{array}$ & $118(60)$ & $74(56)$ \\
\hline Conventional Bronchoscopy & $59(30)$ & $22(17)$ \\
\hline TTNA & $51(26)$ & $48(36)$ \\
\hline Radial EBUS & $8(4)$ & $4(3)$ \\
\hline Lymph Node sampling & $53(27)$ & $28(21)$ \\
\hline Linear EBUS & $48(25)$ & $16(12)$ \\
\hline Mediastinoscopy & $2(1)$ & $2(1)$ \\
\hline EUS & $0(0)$ & $4(3)$ \\
\hline Chamberlain & $2(1)$ & $0(0)$ \\
\hline Lymph Node FNA & $1(<1)$ & $6(<1)$ \\
\hline Surgical Sampling ${ }^{a}$ & $13(7)$ & $20(15)$ \\
\hline Biopsy of Metastases ${ }^{b}$ & $5(3)$ & $6(5)$ \\
\hline No pathologic confirmation & $6(3)$ & $4(3)$ \\
\hline
\end{tabular}

${ }^{a}$ At time of lobectomy or wedge resection

${ }^{\mathrm{b}}$ Includes thoracentesis, medical thoracoscopy, liver biopsy, brain biopsy, and bone biopsy

status and use of EBUS were not associated with longer delays $(p>0.05)$. After adjustment for these variables, investigation within the RIC was associated with a shorter time to treatment ( -24 days, 95\% confidence interval $[\mathrm{CI}]-35$ to -12 days). Among the subset of patients with NSCLC, patients with stage I -IIB tumors had significantly longer delays to treatment (15 days, 95\% CI 3-28) compared to those with later stage tumors when adjusted for investigation within vs. outside RIC, and other confounders.

Quality indicators were compared in the RIC and nonRIC groups (Table 6). PET scans were performed more frequently in early stage patients investigated within the RIC (94\% vs. $82 \%, p=0.05)$. Brain imaging in the context of stage IIIA NSCLC was performed in $51 \%$ of RIC and $38 \%$ of non-RIC patients $(p=n s)$. Neuroimaging for SCLC was performed in $92 \%$ of RIC and $72 \%$ of nonRIC patients $(p=n s)$. A larger proportion of patients investigated via the RIC were discussed at tumor board or evaluated in the multidisciplinary lung cancer clinic ( $74 \%$ vs. $55 \%, p<0.01$ ).

\section{Discussion}

Implementation of a rapid investigation clinic was associated with decreased time between the first visit for suspected lung cancer and first treatment. In multivariate analysis, the difference in time to treatment related to
Table 4 Last imaging test or procedure performed to complete the lung cancer investigation (diagnosis and staging) among patients who received treatment

\begin{tabular}{|c|c|c|}
\hline & \multicolumn{2}{|c|}{$\begin{array}{l}\text { Number of patients in whom } \\
\text { a given test is the last test to } \\
\text { complete the investigation, } \\
\text { among treated patients } \\
(\mathrm{N}=283)\end{array}$} \\
\hline & $\operatorname{RIC}(N=167)$ & $\begin{array}{l}\text { Non-RIC } \\
(N=116)\end{array}$ \\
\hline $\begin{array}{l}\text { Lung mass or peripheral nodule } \\
\text { sampling }\end{array}$ & $12(7)$ & $27(23)$ \\
\hline Conventional Bronchoscopy & $4(2)$ & $4(3)$ \\
\hline TTNA & $7(4)$ & $23(20)$ \\
\hline Radial EBUS & $1(1)$ & - \\
\hline Lymph Node sampling & $26(16)$ & $19(16)$ \\
\hline Linear EBUS & $12(7)$ & $9(8)$ \\
\hline Mediastinoscopy & $10(6)$ & $8(7)$ \\
\hline EUS & $2(1)$ & $1(1)$ \\
\hline Chamberlain & $2(1)$ & $0(0)$ \\
\hline Lymph Node FNA & $1(<1)$ & $1(1)$ \\
\hline Imaging study & $115(69)$ & $64(55)$ \\
\hline CT scan & $19(11)$ & $14(12)$ \\
\hline PET scan & $80(48)$ & $42(36)$ \\
\hline MRI & $9(5)$ & $4(3)$ \\
\hline Ultrasound & $1(1)$ & - \\
\hline Bone scan & $6(4)$ & $4(3)$ \\
\hline Biopsy of Metastases ${ }^{a}$ & $14(8)$ & $6(5)$ \\
\hline N/A & $1(-)$ & - \\
\hline
\end{tabular}

Includes thoracentesis, medical thoracoscopy, liver biopsy, brain biopsy, and bone biopsy

RIC was 24 days, when adjusted for relevant confounders such as sex, age, performance status, inclusion of EBUS and/or PET scan in the investigation, and number of non-diagnostic procedures. The factors associated with significantly longer delays were advanced age, early

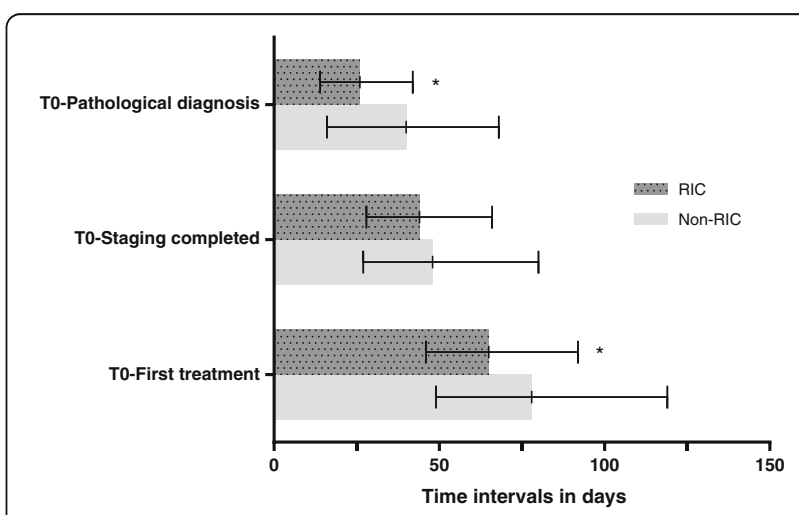

Fig. 1 Time intervals from To to lung cancer diagnosis, staging and first treatment. ${ }^{*} p \leq 0.01$ 
Table 5 Multivariate model of time interval from T0 to first treatment (in days)

\begin{tabular}{|c|c|c|c|c|c|}
\hline \multicolumn{3}{|l|}{ All patients $(N=283)$} & \multicolumn{3}{|l|}{ Patients with NSCLC only $(N=254)$} \\
\hline Characteristic & Beta (days) & $p$-value & Characteristic & Beta (days) & $p$-value \\
\hline $\mathrm{RIC}$ & $-24(-35$ to -12$)$ & $<0.01$ & $\mathrm{RIC}$ & $-24(-37$ to -11$)$ & $<0.01$ \\
\hline Male & $-4(-15$ to 8$)$ & 0.53 & Male & $-2(-14$ to 11$)$ & 0.77 \\
\hline Age $\geq 75$ years & 16 (3 to 30$)$ & 0.02 & Age $\geq 75$ years & $14(0-29)$ & 0.05 \\
\hline$E C O G \geq 2^{a}$ & $1(-16$ to 16$)$ & 0.98 & $E C O G \geq 2^{a}$ & $3(-14$ to 11$)$ & 0.77 \\
\hline NSCLC (vs. SCLC) & 10 (4 to 43$)$ & 0.02 & Stage I-II (vs. Stage III-IV) & $15(3-28)$ & 0.02 \\
\hline PET & 17 (2 to 31$)$ & 0.03 & PET & $13(-4$ to 29$)$ & 0.14 \\
\hline EBUS & $2(-11$ to 14$)$ & 0.20 & EBUS & $-1(-14$ to 12$)$ & 0.90 \\
\hline Number of non-diagnostic procedures & & & Number of non-diagnostic procedures & & \\
\hline 0 & Reference & - & 0 & Reference & - \\
\hline 1 & 20 (6 to 33 ) & $<0.01$ & 1 & 18 (5 to 33 ) & $<0.01$ \\
\hline$\geq 1$ & 37 (15 to 60$)$ & $<0.01$ & $\geq 1$ & 38 (14 to 60$)$ & $<0.01$ \\
\hline
\end{tabular}

Patients treated with palliative intent, patients receiving treatment outside the McGill University Health Centre, and patients with time to treatment greater than 1 year were excluded from this analysis. ${ }^{\text {a }}$ Reference category is patients with ECOG of 0 or 1 NSCLC; SCLC

stage NSCLC, and patients with a first invasive test that was non-diagnostic. Patients investigated within the RIC were more likely to undergo PET scan for early stage lung cancer; they were more likely to be referred to the multidisciplinary lung cancer clinic or have their case reviewed at tumor board. Thus, the rapid investigation clinic improved timeliness of care while improving certain aspects of guideline-concordant care.

The study was based at a single university-affiliated center, which limits the generalizability of the results. The database for RIC patients was maintained prospectively by a trained registrar, with the goal of monitoring investigation delays in real time. In contrast, controls were individuals with a pathological diagnosis of lung cancer identified from the institutional tumor registry, and the investigation path was reviewed retrospectively. However, this definition allowed identification of a comparison group of patients who had access to similar imaging and procedural resources during the study timeframe. The dates and type of tests were easily identified from the institution's clinical information system, so

Table 6 Pre-specified indicators of guideline-concordant investigation

\begin{tabular}{|c|c|c|c|}
\hline & $\mathrm{RIC}(\%)$ & Non-RIC (\%) & $p$-value \\
\hline $\begin{array}{l}\text { PET scans in stage } 1 / I I \\
\text { NSCLC }\end{array}$ & 48/51 (94) & $45 / 55(82)$ & $0.05^{a}$ \\
\hline $\begin{array}{l}\text { Brain imaging in stage } \\
\text { IIIA NSCLC }\end{array}$ & $26 / 51(51)$ & $14 / 37(38)$ & $0.22^{a}$ \\
\hline Brain imaging in SCLC & $24 / 26(92)$ & $5 / 7(72)$ & $0.13^{b}$ \\
\hline $\begin{array}{l}\text { Patient seen in multi- } \\
\text { disciplinary lung cancer } \\
\text { clinic, or case reviewed } \\
\text { at Tumor Board }\end{array}$ & $144 / 195(74)$ & $73 / 132(55)$ & $<0.01^{\mathrm{a}}$ \\
\hline
\end{tabular}

Chi-squared $^{\mathrm{a}}$ or Fisher's exact test ${ }^{\mathrm{b}}$ were used that delays could be accurately measured and compared. Previous authors have reported that advanced disease may be associated with more prompt investigation and treatment $[9,10]$. It is unlikely that sicker patients would be systematically referred to the RIC. In fact, baseline performance status was not significantly different between RIC and non-RIC patients. A larger number of non-RIC patients had early stage NSCLC; however, the RIC-related reduction in delays remained significant after adjustment for stage in the multivariate model of NSCLC patients.

The time required to complete lung cancer staging was comparable in the RIC and non-RIC patients. Several factors may be responsible for lack of change in this regard. EBUS was introduced at our institution at the end of 2008, and was performed by only two operators during the study period. Traditional practice patterns and/or ready availability of certain tests, conventional diagnostic bronchoscopy for example, led to their frequent use in both the RIC and non-RIC patients. In addition, limited access to PET scan delayed completion of staging in both RIC and non-RIC patients. PET scan was the last test needed to complete staging in $48 \%$ or RIC vs. $36 \%$ of non-RIC patients (Table 4). Despite these challenges, the RIC had a positive impact on time to lung cancer treatment.

Previous studies have evaluated delays to diagnosis or treatment of lung cancer. Olsson et al. systematically reviewed studies describing timeliness of care in patients with lung cancer [11]. Time to diagnosis and treatment of lung cancer were frequently longer than recommended. Salomaa et al. examined delays for 132 patients with NSCLC at a Finnish hospital and reported a median delay from specialist visit to diagnosis of 15 days (mean 
55 days), and from diagnosis to treatment of 15 days [12]. More recently a United Kingdom (UK) administrative study of 28,733 patients found that only $43 \%$ of patients were treated within 1 month of diagnosis of lung cancer [13]. A United States of America (USA) study of veterans reported median delays of 42 days for diagnosis and 84 days for first treatment [10]. Wait times for diagnosis and treatment in Canada vary across provinces. In Ontario, median time to diagnosis of lung cancer was 37 days (IQR 29-49 days) [14]; in Manitoba median time from abnormal chest $\mathrm{x}$-ray to tissue diagnosis was 26 days, with more than $25 \%$ of patients waiting longer than 55 days for diagnosis [15]. In Quebec, median time from initial contact with a physician for lung cancer and surgery was 109 days [16]. The variability in measures is partly due to different definitions of "time 0".

Guidelines for timeliness of care vary among countries. The 2011 NICE guidelines suggest an acceptable delay is 2 months from urgent general practitioner (GP) referral to beginning of treatment [5]. In this study, the median delay from T0 to first treatment was 81 days, thus not within the recommended 8 weeks. Significant challenges remain in meeting these targets, as highlighted by additional recent studies from Canada and the USA [17-19]. Avoiding diagnostic delays may be increasingly difficult, as accurate staging requires specific procedures and imaging tests [4]. The goal of the RIC was to centralize management of referrals, improve access to specialized providers and diagnostic tests, and standardize the workup of lung cancer. In essence, we attempted to modify both structure and process elements in order to reduce time to treatment.

A systematic review of studies evaluating diagnostic assessment units in patients with solid tumors reported reduced time to first treatment and greater patient satisfaction [20]. When reviewed systematically in patients with lung cancer, factors associated with improved delays included nurse-led coordination of care and use of a "two-stop" investigation pathway, while a multidisciplinary clinic approach did not result in more timely care [11]. Two studies from the UK prospectively implemented a two-stop pathway at centralized hospitals with a team dedicated to investigation and staging; both decreased time to diagnosis and increased radical treatment rates by scheduling patients for procedures the same day as physician evaluations $[21,22]$. A singlecenter, Veterans' Administration (VA) study from the USA retrospectively reviewed timeliness of care provided in a multidisciplinary clinic with "usual" care provided after the clinic closed. The comparison revealed similar intervals to diagnosis and treatment with a multidisciplinary approach; the authors hypothesized this may have been due in part to absence of a surgeon in the multidisciplinary setting, and existing infrastructure from the previous multidisciplinary clinic [23]. A VA study in Birmingham reported improved lung cancer resection rates after implementation of a "Lung Mass Clinic" staffed by specialists in lung cancer, although the median time to resection was longer than expected (104 days) [24]. These conflicting results highlight the complexity of lung cancer care. Medical complexity was shown to increase delays to treatment in a recent Norwegian study, yet too few of even the least complex patients received timely treatment [25].

The impact of timeliness of care on lung cancer outcomes is unclear. In the systematic review of Olsson et al., the association between timely lung cancer care and patient outcomes were mixed and, at times, paradoxical [11]. A large population-based study of surgical patients demonstrated no influence of time to surgery on survival [26]. A Swedish study of 466 patients treated with curative or palliative intent showed that those with shortest time to treatment had worse survival [27]. Gould et al. investigated 129 veterans with NSCLC and found that more timely care was not associated with better survival. More advanced patients may require more urgent evaluation, thereby decreasing overall survival in patients treated sooner. However, in the subgroup of patients with solitary pulmonary nodules, there was a trend toward improved survival with shorter time to treatment [10]. O'Rourke et al. reported tumor growth while patients waited for radiotherapy treatment by comparing diagnostic and CT simulation scans, suggesting that delays to treatment may be associated with worse outcomes [28].

No study may be sufficiently powered to assess the survival benefit of a rapid access clinic model, and efforts to improve more scalable quality outcomes may be more realistic. Quality gaps have been defined as differences between health-care processes observed in clinical practice and those recommended by evidence-based guidelines [29]. Ost and colleagues examined quality gaps in lung cancer diagnosis and staging, using the Surveillance Epidemiology and End Results (SEER) database and the Texas Cancer Registry. Patients with lung cancer with regional spread and no distant metastases were classified as receiving guideline-consistent care if they underwent mediastinal lymph node sampling as the first invasive test; only $21 \%$ of patients had guidelineconsistent diagnostic evaluations [30]. In the current study, implementation of a rapid access clinic was associated with more frequent guideline-concordant care, based on the quality indicators examined.

\section{Conclusion}

The implementation of a rapid investigation clinic for patients with lung cancer reduced delays to diagnosis and treatment and improved quality of care. Continued 
monitoring of investigation pathways and wait times is necessary to ensure barriers and quality gaps are addressed in a timely manner.

\section{Abbreviations}

ACCP: American College of Chest Physicians; Cl: Confidence interval; CT: Computed tomography; EBUS: Endobronchial ultrasound; ECOG : Eastern Cooperative Oncology Group; EUS: Endoscopic ultrasound; GP: General Practitioner; IQR: Interquartile range; MUHC: McGill University Health Centre; NICE: National Institute for Health and Clinical Excellence; NSCLC: Non-small cell lung cancer; PET: Positron emission tomography; RIC: Rapid Investigation Clinic; SCLC: Small cell lung cancer; SEER: Surveillance Epidemiology and End Results; TTNA: Transthoracic needle aspiration; USA: United States of America; UK: United Kingdom; VA: Veterans' Administration

\section{Acknowledgements}

The authors gratefully acknowledge Ms. Chantal Savard, nurse-clinician for the Rapid Investigation Clinic and Ms. Julie Latreille, registrar. We would like to thank Ms. Pei Zhi Li for assistance with statistical analyses.

\section{Funding}

This project was supported by the Montreal General Hospital Foundation. Dr. Gonzalez is the recipient of an FRQS chercheur-boursier-clinicien award, and a Réseau en Santé Respiratoire du FRQS (RSR) award.

\section{Availability of data and materials}

The datasets used and/or analysed during the current study are available from the corresponding author on reasonable request.

\section{Authors' contributions}

NE and AVG designed the study, interpreted the results and wrote the manuscript. NE was primarily responsible for data collection and analysis. AN participated in data collection and interpretation of the results. KS and LO participated in study design and interpretation of the results. All authors read and approved the final manuscript.

\section{Ethics approval and consent to participate}

The study was approved by the Research Ethics Board of the MUHC.

\section{Consent for publication}

Not applicable.

\section{Competing interests}

The authors declare that they have no competing interests.

\section{Publisher's Note}

Springer Nature remains neutral with regard to jurisdictional claims in published maps and institutional affiliations.

\section{Author details}

${ }^{1}$ Respiratory Epidemiology and Clinical Research Unit, Montreal Chest Institute, McGill University Health Centre, Montreal, QC, Canada. ${ }^{2}$ Respiratory Division, McGill University Health Centre, Montreal, QC, Canada. ${ }^{3}$ Respiratory and Respiratory Critical Care Medicine, Faculty of Medicine, Prince of Songkla University, Songkhla, Thailand.

\section{Received: 25 May 2017 Accepted: 16 November 2017}

\section{Published online: 08 December 2017}

\section{References}

1. Surveillance Epidemiology and End Results Database: National Cancer Institute; Accessed 10 Dec 10, 2013. Available from: http://seer.cancer.gov/.

2. National Lung Screening Trial Research T, Aberle DR, Adams AM, Berg CD, Black WC, Clapp JD, et al. Reduced lung-cancer mortality with low-dose computed tomographic screening. N Engl J Med. Aug 4;365(5):395-409. PubMed PMID: 21714641. Epub 2011/07/01. eng

3. Fischer B, Lassen U, Mortensen J, Larsen S, Loft A, Bertelsen A, et al. Preoperative staging of lung cancer with combined PET-CT. N Engl I Med 2009 Jul 2;361(1):32-9. PubMed PMID: 19571281. Epub 2009/07/03. eng.
4. Silvestri GA, Gonzalez AV, Jantz MA, Margolis ML, Gould MK, Tanoue LT, et al. Methods for staging non-small cell lung cancer: diagnosis and management of lung cancer, 3rd ed: American College of Chest Physicians evidence-based clinical practice guidelines. Chest 2013 May;143(5 Suppl): e211S-50S. PubMed PMID: 23649440. Epub 2013/05/10. eng.

5. NICE. Lung Cancer: Diagnosis and Management CG121 National Institute for Health Care Excellence 201121 April 2011.

6. Ost DE, Yeung SC, Tanoue LT, Gould MK. Clinical and organizational factors in the initial evaluation of patients with lung cancer: diagnosis and management of lung cancer, 3rd ed: American College of Chest Physicians evidence-based clinical practice guidelines. Chest 2013 May;143(5 Suppl): e121S-41S. PubMed PMID: 23649435. Epub 2013/05/10. eng.

7. Detterbeck FC, Boffa DJ, Tanoue LT. The new lung cancer staging system. Chest 2009 Jul;136(1):260-71. PubMed PMID: 19584208. Epub 2009/07/09. eng.

8. Detterbeck FC, Jantz MA, Wallace M, Vansteenkiste J, Silvestri GA, American College of Chest P. Invasive mediastinal staging of lung cancer: ACCP evidence-based clinical practice guidelines (2nd edition). Chest 2007 Sep; 132(3 Suppl):202S-20S. PubMed PMID: 17873169. Epub 2007/10/06. eng.

9. Powell AA, Schultz EM, Ordin DL, Enderle MA, Graham BA, Partin MR, et al. Timeliness across the continuum of care in veterans with lung cancer. J. Thorac. Oncol. 2008 Sep;3(9):951-7. PubMed PMID: 18758295. Epub 2008/09/02. eng.

10. Gould MK, Ghaus SJ, Olsson JK, Schultz EM. Timeliness of care in veterans with non-small cell lung cancer. Chest 2008 May;133(5):1167-73. PubMed PMID: 18263676. Epub 2008/02/12. eng.

11. Olsson JK, Schultz EM, Gould MK. Timeliness of care in patients with lung cancer: a systematic review. Thorax 2009 Sep;64(9):749-56. PubMed PMID: 19717709. Epub 2009/09/01. eng.

12. Salomaa ER, Sallinen S, Hiekkanen H, Liippo K. Delays in the diagnosis and treatment of lung cancer. Chest 2005 Oct;128(4):2282-8. PubMed PMID: 16236885. Epub 2005/10/21. eng

13. Forrest $L F$, Adams J, White M, Rubin G. Factors associated with timeliness of post-primary care referral, diagnosis and treatment for lung cancer: population-based, data-linkage study. Br J Cancer 2014 Oct 28;111(9):184351. PubMed PMID: 25203519. Pubmed Central PMCID: Pmc4453730. Epub 2014/09/10. eng.

14. Grunfeld E, Watters JM, Urquhart R, O'Rourke K, Jaffey J, Maziak DE, et al. A prospective study of peri-diagnostic and surgical wait times for patients with presumptive colorectal, lung, or prostate cancer. Br J Cancer 2009 Jan 13;100(1):56-62. PubMed PMID: 19088720. Epub 2008/12/18. eng.

15. Cheung WY, Butler JR, Kliewer EV, Demers AA, Musto G, Welch S, et al. Analysis of wait times and costs during the peri-diagnostic period for nonsmall cell lung cancer. Lung Cancer. 2011;72(1):125-31. PubMed PMID: 20822826.

16. Liberman M, Liberman D, Sampalis JS, Mulder DS. Delays to surgery in nonsmall-cell lung cancer. Can J Surg 2006 Feb;49(1):31-6. PubMed PMID: 16524140. Epub 2006/03/10. eng.

17. Kim JO, Davis F, Butts C, Winget M. Waiting Time Intervals for Non-small Cell Lung Cancer Diagnosis and Treatment in Alberta: Quantification of Intervals and Identification of Risk Factors Associated with Delays. Clin. Oncol. (R. Coll. Radiol.). 2016 Dec; 28(12):750-9. PubMed PMID: 27357099.

18. Nadpara P, Madhavan SS, Tworek C. Guideline-concordant timely lung cancer care and prognosis among elderly patients in the United States: a population-based study. Cancer Epidemiol 2015 Dec;39(6):1136-1144. PubMed PMID: 26138902. Pubmed Central PMCID: 4679644.

19. Vidaver RM, Shershneva MB, Hetzel SJ, Holden TR, Campbell TC. Typical time to treatment of patients with lung cancer in a multisite, US-based study. J. Oncol. Pract. 2016 Jun;12(6):e643-53. PubMed PMID:27143146.

20. Brouwers M, Oliver TK, Crawford J, Ellison P, Evans WK, Gagliardi A, et al. Cancer diagnostic assessment programs: standards for the organization of care in Ontario. Curr Oncol 2009 Dec;16(6):29-41. PubMed PMID: 20016744. Epub 2009/12/18. eng.

21. Murray PV, O'Brien ME, Sayer R, Cooke N, Knowles G, Miller AC, et al. The pathway study: results of a pilot feasibility study in patients suspected of having lung carcinoma investigated in a conventional chest clinic setting compared to a centralised two-stop pathway. Lung Cancer 2003 Dec;42(3): 283-90. PubMed PMID: 14644515. Epub 2003/12/04. eng.

22. Laroche C, Wells F, Coulden R, Stewart S, Goddard M, Lowry E, et al. Improving surgical resection rate in lung cancer. Thorax 1998 Jun;53(6):4459. PubMed PMID: 9713441. Pubmed Central PMCID: 1745249. Epub 1998/ 08/26. eng. 
23. Riedel RF, Wang X, McCormack M, Toloza E, Montana GS, Schreiber G, et al. Impact of a multidisciplinary thoracic oncology clinic on the timeliness of care. J. Thorac. Oncol. 2006 Sep;1 (7):692-6. PubMed PMID: 17409938.

24. Dransfield MT, Lock BJ, Garver RI, Jr. Improving the lung cancer resection rate in the US Department of veterans affairs health system. Clin. Lung Cancer 2006 Jan;7(4):268-72. PubMed PMID: 16512981. Epub 2006/03/04. eng.

25. Stokstad T, Sorhaug S, Amundsen T, Gronberg BH. Medical complexity and time to lung cancer treatment - a three-year retrospective chart review. BMC Health Serv Res 2017 Jan 17;17(1):45. PubMed PMID: 28095840. Pubmed Central PMCID: 5240346.

26. Aragoneses FG, Moreno N, Leon P, Fontan EG, Folque E. Influence of delays on survival in the surgical treatment of bronchogenic carcinoma. Lung Cancer 2002 Apr;36(1):59-63. PubMed PMID: 11891034. Epub 2002/03/14. eng.

27. Myrdal G, Lambe M, Hillerdal G, Lamberg K, Agustsson T, Stahle E. Effect of delays on prognosis in patients with non-small cell lung cancer. Thorax 2004 Jan;59(1):45-9. PubMed PMID: 14694247. Epub 2003/12/25. eng.

28. O'Rourke N, Edwards R. Lung cancer treatment waiting times and tumour growth. Clin. Oncol. (R. Coll. Radiol.). 2000;12(3):141-4. PubMed PMID: 10942328. Epub 2000/08/15. eng.

29. Shojania K MK, Wachter R. Owens DK, eds. Closing The Quality Gap: A Critical Analysis of Quality Improvement Strategies. Volume 1-Series Overview and Methodology. Agency for Health Care Research and Quality Publication. 2004 (04-0051-1).

30. Ost DE, Niu J, Elting LS, Buchholz TA, Giordano SH. Quality gaps and comparative effectiveness in lung cancer staging and diagnosis. Chest 2014 Feb 1;145(2):331-45. PubMed PMID: 24091637. Epub 2013/10/05. eng.

\section{Submit your next manuscript to BioMed Central and we will help you at every step:}

- We accept pre-submission inquiries

- Our selector tool helps you to find the most relevant journal

- We provide round the clock customer support

- Convenient online submission

- Thorough peer review

- Inclusion in PubMed and all major indexing services

- Maximum visibility for your research

Submit your manuscript at www.biomedcentral.com/submit

) Biomed Central 